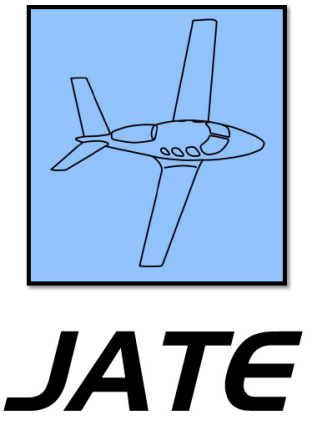

Journal of Aviation Technology and Engineering 6:2 (2017) 33-49

\title{
A Safety Management Model for FAR 141 Approved Flight Schools
}

\author{
Flavio A. C. Mendonca and Thomas Q. Carney \\ (Purdue University)
}

\begin{abstract}
The Safety Management Annex (Annex 19), which became applicable in November 2013, consolidates safety management provisions previously contained in six other International Civil Aviation Organization (ICAO) Annexes, and will serve as a resource for overarching state safety management responsibilities. Through Annex 19, ICAO has required that its member states develop and implement safety management systems (SMS) to improve safety. This mandate includes an approved training organization that is exposed to aviation safety risks. In 2015, the FAA published AC 120-92B to provide guidance material for certificate holders operating under FAR 121, to implement and maintain an SMS. This AC may also be used by other aviation service providers interested in voluntarily developing an SMS based on the requirements in 14 Code of Federal Regulations Part 5 (14 CFR Part 5). There are numerous reasons for SMS implementation going beyond simple compliance with international or national guidelines. The most important of these is safety enhancement, because it is an intrinsic requirement of the aviation system. There is a vast body of literature regarding SMS, but none of it suggests a model to a specific service provider. The implementation of an SMS model tailored to FAR 141 approved flight schools has the strong potential to yield safety enhancement, through a structured management system to control risks in operation. The purpose of this study is to develop a safety management model for FAR 141 operators, based on the ICAO SMS outlined in Annex 19, and current FAA requirements and safety protocols, as outlined in AC 120-92B.
\end{abstract}

\section{Introduction}

According to the Federal Aviation Administration (FAA), the world economy benefits greatly from the ability of aviation operations to transport people and cargo worldwide, quickly and safely (FAA, 2015a). The related statistics are impressive. The aviation industry, both directly and indirectly, supports the employment of 56.6 million people, contributes over $\$ 2$ trillion to global gross domestic product (GDP), and carries over 2.5 billion passengers and \$5.3 trillion worth of cargo annually (ICAO, 2013a). Therefore, continuous improvement in aviation safety is paramount to ensuring the aviation industry will continue to play a major role in driving sustainable, economic, and social development around the world (ICAO, 2013b; Manuele, 2003).

With the current low accident rate, it is increasingly difficult to make further improvements to the level of safety by using reactive analysis of past aircraft accidents and the introduction of corrective actions through safety recommendations (ICAO, 2013b). Thus, a modern safety management approach has been developed that leads to safety risks being addressed more proactively by regulators and aviation service providers, rather than relying solely on inspection and remedial actions on end products. This innovation in aviation system safety constitutes a safety management system (SMS), an expression 
indicating that safety efforts are most effective when made a fully integrated part of the business operation (Ludwig, Andrews, Veen, \& Laqui, 2007; Gnehm, 2013).

A safety management system prompts an operator to actively identify potential hazards, analyze them, and create measures that will minimize the risks involved with these hazards (DeFusco, Junior, Cooley, \& Landry, 2015; Mendonca, 2008). According to Galotti, Rao, and Maurino (2006), the systematic approach provides for participation of all members of the organization in the SMS implementation. An SMS provides aviation operators the tools to anticipate and address safety hazards before they contribute to an accident (Junior et al., 2009). The systemic approach to managing safety also provides senior-management with the capacity to deal effectively with near misses and mishaps so that valuable lessons are applied to enhance efficiency and safety. The SMS approach reduces the risk of accidents, improves personnel morale and productivity, may reduce insurance costs, and is generally good for business.

With the development of Annex 19 - Safety Management, updated guidance material, and a dedicated website, ICAO aims to stress the importance of the overall safety performance in all aspects of air transport operations (Gnehm, 2013). The new Annex on safety management and companion documents, including the Safety Management Manual (Doc 9859), will provide a sound basis for global aviation safety. The Global Aviation Safety Plan (GASP) midterm objective is that all ICAO states should fully implement their State Safety Program (SSP) framework by 2022 to facilitate the proactive management of safety risks (Gnehm, 2013; Graham, 2015; ICAO, 2013a). Each State, through its SSP and safety legislative framework, will require that certain service providers, including FAR 141 approved flight schools, develop and implement an SMS. The SMS should allow for the effective identification of systemic safety hazards and their mitigation (ICAO, 2013c). The implementation of the SMS model proposed herein will allow FAR 141 approved school certificate holders to develop a realistic and efficient balance between safety and student completions. In addition, it will assure compliance with national regulations and ICAO Standards and Recommended Practices (SARPs) (FAA, 2015b; ICAO, 2013a; Junior et al., 2009).

\section{Literature Review}

A review of FAR Part 141 approved flight school requirements, as well as the FAA and ICAO SMS provisions and best practices used to manage aviation safety, was conducted. This section discusses how an SMS can assist the training organization's leadership, management teams, and employees in making effective and informed safety decisions, and proposes a systemic model to be used by these organizations while managing risks in daily operations (FAA, 2015b).

\section{The Evolution of Aviation Safety}

The evolution of safety management in the air transportation industry can be divided into three eras. During the organizational era, which began in the 1990s, the management of safety began to be viewed from a systemic perspective, encompassing organizational, human, and technical factors. The concept of the "organizational accident" was introduced, to take into account the impact of the safety culture and organizational policies on the effectiveness of safety risk controls. In addition, the reactive approach through the investigation of aircraft accidents and incidents was supplemented with a new, proactive approach to managing safety (ICAO, 2013b). This safety management approach is based on routine collection and analysis of safety data using proactive and reactive methodologies to continuously and effectively identify and address safety risks (ICAO, 2013c; Maurino, Reason, Johnston, \& Lee, 1995). These enhancements form the rationale for moving toward a safety management approach (ICAO, 2013c).

\section{Organizational Accidents}

The aviation industry, like other complex technical fields, is in the age of organizational accidents (Lupoli, 2006; Reason, 1997; Reason, 1998). Preexisting and often long-standing latent conditions arising in the organizational and managerial sectors, can combine with local triggering conditions to penetrate or bypass the aviation system's multiple defenses and cause accidents (Maurino et al., 1995). The organizational accidents theory focuses on events beyond the failures of front line employees to preexisting conditions, also known as latent conditions, which result from improper decisions made by high-level decisionmakers. It is these incorrect decisions that can permit active failures to occur. Management should build defenses by creating a culture in which precursor events are detected and promptly corrected. This approach has the greatest potential for preventing accidents in an organization (Lupoli, 2006; Reason, 1998; Wells \& Rodrigues, 2003).

To prevent latent conditions from causing accidents, it is paramount for an organization to develop and maintain a healthy safety culture (Antonsen, 2009; Cooper, 2000; Lupoli, 2006; Reason, 1998; Wiegmann, Thaden, \& Gibbons, 2007). A healthy safety culture is capable of continuing efforts toward the goal of maximum safety health, regardless of the leadership's personality and current commercial concerns (Choudhry, Fang, \& Mohamed, 2007). Piers, Montijn, and Balk (2009) defined safety culture as "the set of enduring values and attitudes regarding safety issues, shared by every member of every level of an organization (p. 5).

A safety culture is composed of four subcomponents: the just culture, the reporting culture, the informed culture, and the learning culture (Reason, 1997). Organizations with a healthy safety culture are characterized by communications 
founded on mutual trust, by shared perceptions of the importance of safety, and by confidence in the efficacy of preventive measures. Table 1 (see Appendix) presents the characteristics of different safety cultures.

Organizational factors are often identified as causal factors in aircraft accidents. Thus, management should build defenses by creating a safety culture in which precursor events, or latent conditions are detected and promptly corrected (Reason, 1998). This approach has the greatest potential for preventing accidents in an organization (Piers et al., 2009; Reason, 1998; Wood, 2003).

\section{System Safety}

System safety is "the application of engineering and management principles, criteria, and techniques to optimize safety" (FAA, 2010, p. 3.2). System safety techniques are effective in identifying and especially eliminating hazards, and in recommending risk reduction methods for mitigating residual risks (FAA, 2010; Lu, Wetmore, \& Przetak, 2006, Vincoli, 2006). A risk reduction method could be in the format of a system modification, safety and/or warning devices, and implementation of new procedures and corresponding training. The system safety doctrine is effective in accident prevention and safety enhancement (Lu et al., 2006). The safety manager could use system safety tools (see Figure 2, in the Appendix) to identify hazards associated with the operation of a flight school, and introduce the adequate countermeasures to mitigate or reduce risks to an acceptable level (FAA, 2010; Lu, Bos, \& Caldwell, 2007; Mendonca, 2008; Vincoli, 2006).

\section{FAR 141 Approved Flight Schools}

Flight training in the United States is conducted under the auspices of the FAA in accordance with federal regulations laid out in Title 14 of the Code of Federal Regulations (14 CFR) Parts 61, 141, or 142 (FAA, 2016). Flight schools operating under 14 CFR Part 141 are certificated by the FAA. Application for certification under Part 141 is voluntary. However, the school must meet stringent standards to ensure a high level of safety. Moreover, the requirements for personnel, aircraft, facilities, and operating rules, as well as an established curriculum, allow these organizations to complete certificates and ratings more efficiently (requiring fewer flight hours).

Several studies have addressed safety issues that could contribute to aircraft accidents within Part 141 approved flight schools. A study by Cassens (2010) identified that students were not being provided opportunities to develop and apply their aeronautical decision making (ADM) skills. Even though the FAA mandates that applicants for licenses should demonstrate good ADM skills (FAA, 1991), flight instructors were not incorporating instructional methods to teach the elements of ADM. According to the FAA (2016),
ADM is a systemic approach used by pilots to manage aviation risks. Cassens (2010) recommended that approved flight schools introduce processes to periodically determine the status of ADM instruction and detect any need for improvement.

Adjekum (2014) conducted an assessment of the prevailing safety culture of a Part 141 approved flight school for pilots. The study occurred after the implementation of a phased component of an SMS. The research project identified significant variances in the perception of the participants' safety culture. The researcher identified that differences in national cultures, flight experience, and years spent in the flight program can play a significant role in the safety culture of pilots in a collegiate aviation program. Adjekum (2014) recommended further studies addressing the safety culture of Part 141 flight schools. Such research efforts are vital to establish best practices for creating a Safety Management System, before FAA mandates the implementation of an SMS program.

One-third of the midair collisions involving general aviation (GA) from 2000 through 2012 occurred during instructional flights (Cassens, 2015). The purpose of Cassens' (2015) research was to assess whether behaviorbased safety could effectively motivate Part 141 pilots to follow FAA recommendations and explicit procedures designed to prevent midair collisions. According to Cassens (2015), the organization's policies created latent conditions (e.g., pressure to complete a flight lesson at the expense of clearing turns) that could contribute to midair collisions. The author provided recommendations to address the training of pilots as a safety tool to prevent midair collisions. Additionally, the resarcher recommended that Part 141 flight schools should frequently review their policies to mitigate latent conditions.

Adjekum et al. (2015) conducted a study to determine the relationship between safety culture perceptions and predicted safety reporting behavior of five collegiate aviation flight programs in the US. The authors identified a negative relationship between safety reporting behavior and age. Moreover, the researchers identified operational pressures to complete flight lessons at the expense of safety. Finally, the investigators found that some pilots demonstrated a poor safety culture, because they were not confident that the safety reporting system was anonymous. Pilots were apprehensive that the information provided through the system could be used for purposes other than safety (e.g., administrative purposes). According to Adjekum and colleagues (2015), a robust safety foundation and framework can positively affect the safety culture of Part 141 flight schools. Most importantly, there is a need for the implementation of SMS concepts to enhance the safety culture and consequently improve aviation safety within collegiate flight schools.

According to the Aircraft Owners and Pilots Association (AOPA) Air Safety Institute (2016), there were 52 fixed 
wing GA aircraft accidents identified as Visual Meteorological Conditions (VMC) into Instrument Meteorological Conditions (IMC), from 2001 through 2015. All of them involved fatalities. Keller (2015) developed two training protocols to enhance GA pilots' knowledge, skills, and abilities to safely manage deteriorating weather conditions. The target population for the study was composed of noninstrument rated private pilots, and included Part 141 aviators. Some pilots misperceived the risks involved in flying into deteriorating weather conditions, while others over-relied on technology to avoid an accident, and a few were influenced by their overwhelming desire to arrive at their destination. Keller recommended enhanced certificate training to improve novice and expert pilots' competency to mitigate the risk of VMC into IMC mishaps.

\section{Safety Management Systems}

Freiwald, Anderson, and Baker (2013) conducted a research project involving a multinational flight training organization, which had two campuses in the US. The study was prompted by a series of aircraft accidents and incidents that resulted in hull losses and four fatalities. At the time of the study, the organization did not have any proactive safety strategy (e.g., SMS) implemented, only a quality assurance program. According to the authors, the organization had an unhealthy safety culture. For instance, no participants were familiar with the organization's safety reporting system. In addition, top management depended upon the individuals' values and fear of being involved in a mishap, which could ruin their careers, as the best strategy to prevent accidents. The researchers presented the lack of safety accountability within the members of the organization as the strongest finding of the study. Freiwald and colleagues (2013) recommended the implementation of an SMS as the most effective approach to prevent aircraft accidents in the organization studied.

The Safety Management Annex (Annex 19), representing the first new ICAO Annex adopted in over thirty years, consolidated SARPs previously contained in six other ICAO Annexes, and has served since 2013 as a resource for ICAO member states' safety management responsibilities (Gnehm, 2013). Annex 19 requires ICAO member states to establish a State Safety Program (SSP) for the regulation and management of safety (ICAO, 2013c). As a part of its SSP, each state should require certain service providers under its authority to implement an SMS (ICAO, 2013c). This mandate includes training organizations in accordance with Annex 1 (ICAO, 2011; ICAO, 2013c).

An SMS is an organization-wide comprehensive and preventive approach to assure the safe operation of an aircraft through effective management of safety risks (ICAO, 2013c). An SMS provides an FAR 141 operator with the capacity to anticipate and address safety risks before they lead to an accident (Chen \& Chen, 2014; Junior et. al.,
2009). Additionally, an SMS provides management with the ability to effectively deal with safety hazards so that valuable lessons are applied to improve safety and efficiency (Cardoso, Maurino \& Fernandez, 2008a; Liou, Yen, \& Tzeng, 2008). Aviation service providers, including training organizations, typically implement enterprise-wide management systems, such as a quality management system (QMS), SMS, documentation management system (DMS), and fatigue risk management system (FRMS). All of those programs give direction through some type of governance system. An SMS will integrate the different management systems as functional components of the overarching organizational management system, in order to enhance organizational safety and to support the delivery of products and services (Cardoso, Maurino, \& Fernandez, 2008b; ICAO, 2013c). There are various easily identifiable benefits to such integration, which include: avoidance of redundancy (reduce costs); reduction of all-embracing organizational risks (increase profitability); balance of potentially conflicting objectives; and elimination of potentially conflicting responsibilities, accountabilities, and relationships. As a result, the SMS approach reduces losses, improves productivity, and is generally good for business (Cardoso, Maurino, \& Fernandez, 2008a; ICAO, 2013c; Junior et al., 2009).

Federal regulation 14 CFR Part 5 provides a basic set of processes integral to an effective SMS, but does not specify particular methods for implementing these processes (FAA, 2015b). Moreover, the requirements of 14 CFR Part 5, in alignment with Annex 19, were designed to be scalable, allowing operators of different sizes and complexities to integrate safety management practices into their unique business models. Therefore, organizations of different sizes can meet those requirements in different ways. The SMS components and related elements do not need to be extensive or complex to be effective. In fact, operators should use existing safety systems, programs, processes, and resources to identify, document, and track safety issues to resolution (DeFusco et al., 2015; Junior et al., 2009; Ludwig et al., 2007; Volkmer, 2011).

ICAO (2013c) introduced a framework for SMS implementation by relevant aviation service providers. It is important to note that the implementation of the framework should be commensurate with the size of the organization and the complexity of the products or services provided. The framework includes four components and twelve elements, representing the minimum requirements for SMS implementation. The four components, combined with the twelve elements that comprise the ICAO SMS framework, are shown in Table 2 (see Appendix).

The safety policy outlines the principles, processes, and methods of the organization's SMS to achieve the desired safety outcomes (ICAO, 2013b). The policy establishes a senior management's commitment to incorporate and continually improve safety in all aspects of its activities. Safety accountabilities and responsibilities should be included in 
the SMS safety policy and promulgated throughout the organization. In addition, the SMS must include a definition of the levels of management having authority to make decisions regarding safety risk tolerability. The appointment of a qualified safety manager is key to the effective implementation and the development and maintenance of an effective SMS (ICAO, 2013c; Stolzer, Halford, \& Goglia, 2010).

Flight schools are subject to an array of emergencies that warrant actions to save lives and to protect property and public health (Freiwald et al., 2013; Junior et al., 2009; Mendonca, 2008). It is unlikely that such organizations will have sufficient resources to respond to every emergency situation independently; therefore, it is paramount to be prepared so that the organization can respond quickly, efficiently, and effectively. The SMS documentation should include all written documents and materials that contain information, procedures, and records necessary to conduct business (Junior et al., 2009; Ludwig et al., 2007). The SMS documentation facilitates the organization's internal administration, communication, and maintenance of the SMS (ICAO, 2013c). Moreover, it supports continuity and standardization of organizational processes.

FAR 141 operators should ensure that the safety risks encountered in aviation activities are controlled, in order to achieve their safety performance targets (Bastos, 2005; FAA, 2009; FAA, 2015b; ICAO, 2013c). This process, known as safety risk management (SRM), includes hazard identification, safety risk assessment, and the implementation of appropriate remediation measures (see Figure 3, in the Appendix). Safety assurance (SA) consists of processes and activities undertaken by the service provider to determine whether the SMS is operating according to expectations and requirements (FAA, 2015b; ICAO, 2013b; Junior et al., 2009). The service provider should continually monitor its internal processes, as well as its operating environment to detect changes or deviations that may introduce emerging safety risks or degrade existing risk controls (FAA, 2015b). Following the FAA (2015b), an indispensable aspect to positive safety performance is the safety culture of the organization. The concept of safety culture underlies the management of safety and is the basis for the SMS requirements established in 14 CFR Part 5. The safety promotion component encourages a positive safety culture, and creates an environment conducive to achievement of the service provider's safety objectives. An organizational safety effort cannot succeed solely by mandate or strict adherence to policies. Rather, this is achieved through the combination of technical competence that is continually enhanced through training and education, effective communications, and information sharing. Junior and colleagues (2009) suggested that the four pillars of an effective SMS contribute to a robust safety culture.

According to ICAO (2013c), the SMS of a training organization "shall be commensurate with the size of the service provider and the complexity of its aviation products or services" (p. 23). The FAA (2015b) adds that an SMS does not need to be complex or expensive in order to be effective. If the SMS ensures the active commitment and involvement of the senior and operational leaders, fosters the development of a safety culture, helps workers to stay vigilant in looking for new risks during operations, and assures that personnel will be supported in decisions made in the interest of safety, the flight school has an effective SMS that can lead to reduced material losses and enhanced productivity (FAA, 2015b; Manuele, 2003).

An SMS will be most effective if it is built upon existing safety processes and practices. Additionally, it should be tailored to the organization's safety culture, complexity, and operating environment. Before designing the SMS, the service provider should identify the SMS practices already in place (gap analysis). According to the U.S. Department of Transportation (DOT) (2015), certificate holders are likely to already have many of the SMS elements in their current safety practices and operational processes. Even though some of those processes and practices may not entirely fulfill the requirements of Advisory Circular (AC) $120-92 B$, usually because they may be limited in scope and interoperability, certain regulatory and voluntary programs and processes may be appropriate for inclusion in the organization's SMS (FAA, 2015b; ICAO, 2013c; Junior et al., 2009). Table 3 (see Appendix) provides examples of existing processes and safety programs that could be integrated in the SMS in order to satisfy the FAA SMS requirements.

\section{SMS Development and Implementation Costs}

Few studies have addressed the costs of developing and implementing an SMS. The U.S. DOT estimated the costs of SMS implementation by Part 121 operators to be $\$ 224.3$ million, from 2014 through 2023 (DOT, 2015). The compliance costs for air carriers with a fleet of nine or less airplanes will average $\$ 164,500$ per year. For airlines having between 10 to 47 airplanes, the costs will average $\$ 206,400$ a year. The costs include labor wages and training, expansion of existing programs, and development of an SMS implementation plan. However, it is estimated that the economic benefits of SMS implementation by Part 121 operators will range from $\$ 205$ million, through $\$ 472.3$ million, in the same period, considering airlines will mitigate the safety risks identified through the SMS processes. The DOT (2015) notes that costs can be reduced because most air carriers already have SMS processes implemented (e.g., operators maintain training records).

An SMS committee was established in 2016 at the School of Aviation and Transportation Technology (SATT) at Purdue University to conduct a study addressing the establishment of an SMS within the SATT. The SMS committee identified several SMS processes already implemented 
at Purdue University (e.g., safety reporting systems, and a safety committee). The SMS committee also identified a need to involve senior faculty and staff in the SMS processes. The Purdue SMS committee contacted colleagues at a peer university in the US for discussion and guidance relative to their SMS and flight operations quality assurance (FOQA) implementation. In sharing their experiences, the peer university's leaders noted they received a two-day training grant to learn about the SMS program and processes, and how to create and implement an SMS into their organization. They also attended a two-week training program held by the FAA at the FAA Training Center to learn the nuances of using an SMS. The Purdue SMS committee estimated the cost of SMS development and implementation to be around $\$ 228,000$ in the first year, with continuing annual costs averaging $\$ 190,000$. The costs for the first year encompass initial training for faculty and staff, and the continuing annual costs. The continuing annual costs include a full-time SMS manager, a full-time assistant manager, Purdue students' partial assignments, and recurrent training and conferences. ICAO adoption of Annex 19 largely consolidated existing safety provisions into a single Annex. Therefore, the implementation of these SARPs will result in minimal costs. Most importantly, the transition to safety management processes will provide safety benefits that will significantly outweigh any SMS development and implementation costs (ICAO, 2012).

\section{The Federal Aviation Administration}

The ICAO safety management provisions are targeted on two audience groups, states and service providers. Moreover, they provide the high-level standards states must implement to fulfill their safety management responsibilities in order to ensure the safe operation of an aircraft (ICAO, 2013c). The FAA is the agency that regulates and oversees commercial aviation in the US (Johnson \& Gonzalez, 2013). The agency's leading concerns are both the promotion and the regulation of civil aviation, to ensure safe and orderly growth (Wells \& Wensveen, 2004). FAA AC 120-92B requires certificate holders authorized to conduct operations under FAR 121 to develop an SMS that meets the requirements of 14 CFR Part 5 and is acceptable to the FAA, by March 2018 (FAA, 2015b; Foxx, 2015). In addition, this document can also be used by other aviation service providers interested in voluntarily developing an SMS. The FAA is considering SMS requirements for Part 139 and Part 21 operators; however, there is currently no timetable for that (S. VanBuren, personal communication, September 16, 2016). Additionally, the FAA has established an SMS Voluntary Program (SMSVP) for non-121 Certificate Holders, including Part 141 Pilot Schools (FAA, 2015c). The Agency can assist FAR 141 approved flight schools during development and implementation of an SMS.

The approval of a training organization by a state will be dependent upon the organization demonstrating compliance with the relevant requirements in ICAO Annexes 1 and 19 (ICAO, 2013c). FAA (2015b) guidance notes that compliance with AC120-92B will ensure compliance with the ICAO SMS Standards and Recommended Practices (SARPs), in addition to other benefits (see Table 4, in the Appendix).

\section{Methodology}

For this study, the researchers utilized qualitative case methodology. In a qualitative case study, a particular program is studied in-depth for learning more about a document, a technically distinctive situation, or a suggested resolution (Leedy \& Ormrod, 2005; Yin, 2014). Case studies are commonly used to help researchers bridge the gap between foundational studies and practice (Berg, 2001; Patton, 2015). Additionally, case studies allow researchers to build a theory or propose models that expand and generalize theories and concepts (Yin, 2014). The cases selected for this research are the ICAO SMS concepts and framework, and AC120-92B.

An SMS should, at a minimum, develop and maintain a healthy safety culture, proactively identify safety hazards, mitigate or eliminate risks through appropriate safety measures, and provide for constant monitoring and assessment of the safety level achieved to ensure the organization is meeting or exceeding its safety objectives (ICAO, 2013b; FAA, 2015b). This situation opened a door for research, in terms of designing an SMS model for FAR 141 certificated flight schools.

In search of a general management method to allow FAR 141 operators to spawn a realistic and efficient balance between safety and productivity, the authors developed an SMS model for use by FAR 141 approved flight schools. The model was developed based upon different views on safety protocols and the ICAO and FAA SMS concepts. The internal validity of this study is ensured by the triangulation strategy from multiple sources of data and information to support a particular theory (Decrop, 1999; Leedy \& Ormrod, 2005; Patton, 2015). The external validity was enhanced through the theoretical framework used as the foundation for the SMS model, for which validity and reliability are recognized. This strong theoretical framework helped to ensure the external validity of the research project (Leedy \& Ormrod, 2005). The proposed SMS model (see Figure 1) may be adapted to the needs and characteristics of different Part 141 operators. This can be done by establishing safety objectives that are appropriate for the organization, integrating other existing management systems, choosing additional safety risk management strategies that are tailored to their businesses, or by a combination of these.

This SMS model is appropriate for the size and complexity of the operation of any FAR 141 approved flight school. The model includes processes to establish responsibilities and accountabilities for safety, identifies safety 


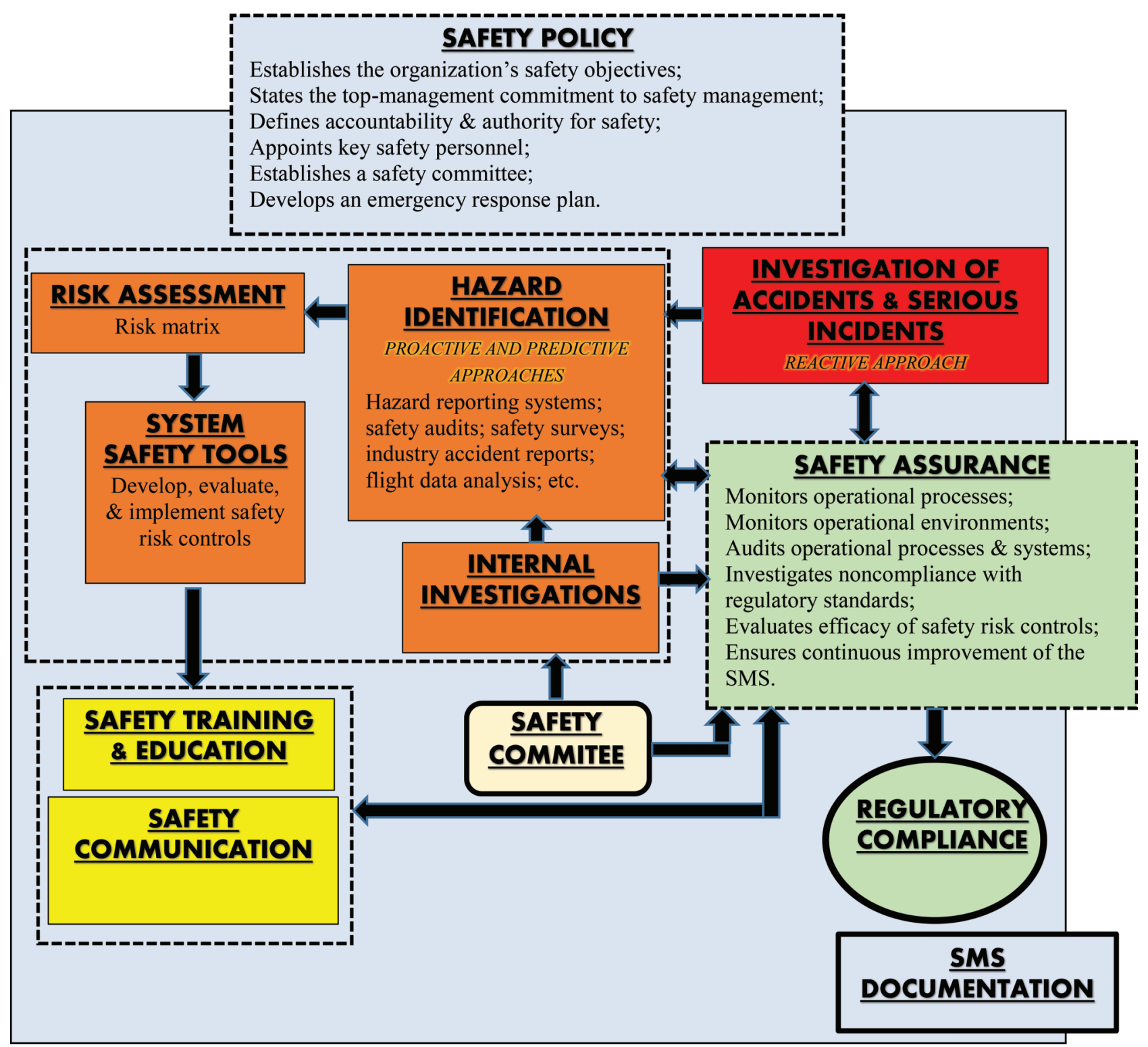

Figure 1. Safety management system (SMS) model for FAR 141 approved flight schools.

hazards, and assesses the associated risks. This framework model facilitates development and implementation of safety risk controls necessary to maintain an acceptable level of safety, and development and maintenance of a healthy safety culture. Finally, the model establishes provisions for continuous monitoring and regular assessment of the appropriateness and effectiveness of safety management activities (ICAO, 2013c). Most importantly, the proposed framework is in alignment with ICAO SARPs and AC120-92B requirements.

\section{Discussion}

Implementation of an SMS will give an approved flight school a set of business processes and management tools to examine the data collected during routine operations.
In addition, it will provide the tools to identify trends that might eventually lead to mishaps, implement safety risk controls to mitigate risks, and monitor the program's effectiveness (Foxx, 2015, Ludwig et al., 2007). The pillars of an effective SMS are the essential ingredients to build and maintain a strong safety culture (Junior et al., 2009; Mendonca, 2008). Finally, an SMS will assist managers with their constant challenge of balancing costs, volume of operations, and safety (Junior et al., 2009).

\section{Safety Policy}

The proposed model is composed of twelve subsystems (see Figure 1) including the four components of an SMS (ICAO, 2013c). Management commitment to safety is the backbone of an SMS. The safety policy specifies the 
SMS high-level concepts; additionally, it describes the topmanagement responsibility, authority, accountability and expectations for safety. Most importantly, the policy, in providing the basis for the growth of a healthy safety culture, ensures that safety is a core value for the organization (Junior et al., 2009; FAA, 2015b; Stolzer et al., 2010). By embracing the safety policy, members of the entire organization will be able to identify and understand that safety is a priority for senior management and is expected to be a priority for them as well (Junior et al., 2009). The safety policy will help identify the accountabilities of all managers and members of the flight school that, irrespective of other functions, are responsible for the organization's safety performance. The safety policy will also include a definition of the levels of management with the authority to make decisions regarding safety risk tolerance (ICAO, 2013c).

The appointment of a qualified safety manager is paramount to the effective development, implementation, and functioning of an SMS (ICAO, 2013c). The safety or SMS manager is the individual responsible for the development and maintenance of an effective SMS. The SMS manager should have access to both senior management and line personnel, so as to advise them on safety matters and facilitate hazard identification, safety risk analysis, and mitigation.

The safety committee is a group of very high-level aviation professionals, chaired by the accountable executive. It is composed of senior managers to provide a forum to discuss safety issues from different perspectives, especially for hazards requiring a broader viewpoint (Junior et al., 2009; Mendonca, 2008). Moreover, strategies to eliminate or mitigate risks must be developed with clearly established accountabilities. Thus, the safety committee provides the most effective forum to achieve the objectives of resource allocation, assignment of responsibilities, and to assess the effectiveness and efficiency of safety risk control strategies. Most importantly, when managers realize that their suggestions to mitigate safety hazards are objectively reviewed and accepted by the safety committee, their participation in the SMS tends to improve. In the proposed SMS model, the safety committee roles may include: making safety recommendations, reviewing safety audits and reports for the adequacy of corrective risk assessments and controls, evaluating cost-benefit analysis of safety recommendations, and providing high-level expertise in the risk management process, including the development and implementation of safety risk controls (ICAO, 2013c). How an approved flight school fares if faced with an aircraft accident or serious incident will depend upon how well it handles the first few hours following the occurrence. An emergency response plan (ERP) provides the basis for a systematic approach to managing the organization's affairs in the aftermath of a significant unplanned event — in the worst case, a major accident. Aircraft accidents are rare events; therefore, it is paramount to be prepared, should one occur (ICAO, 2013c).
The ERP could also address situations such as a major power outage, loss of radar and/or communications, or other issues that may compromise aviation safety. An emergency response plan (ERP) outlines in writing what should be done during an aviation crisis and who is responsible for each action. Successful response to an emergency, which reflects an effective SMS, begins with effective planning (FAA, 2015b; ICAO, 2013c; Ludwig et al., 2007).

\section{Safety Risk Management}

Most activities performed by a flight school involve a certain level of risk (Cassens, 2010, 2015; Adjekum, 2014; Adjekum et al., 2015; Keller, 2015; FAA, 2009). Thus, managers must make decisions on risk acceptability, otherwise they will simply push the decision down toward the front-line operation, usually the pilots or flight instructors, who will face the risk and will have no alternative but to make decisions without the desired assessment (Lupoli, 2006; Mendonca, 2008). The objective of the risk management process is to focus safety efforts on hazards posing the greatest risks (Lu et al., 2006). Hazard identification is a vital step in this process because risk assessment cannot deal with concealed risks. Therefore, an approved flight school should develop and maintain formal processes to ensure that hazards in operations are identified (Bastos, 2005). Following ICAO (2013c), the identification of hazards should be based upon a combination of reactive, proactive, and predictive methods of safety data collection (see Figure 1). A safety culture in which all of the organization's people are motivated and persuaded to report hazards will provide the data necessary for the SMS to be effective (Reason, 1997, 1998; Volkmer, 2011).

A characteristic of aircraft accidents is that their severity is difficult to anticipate (Bastos, 2005; Wood \& Sweginnis, 2006). Risk analysis techniques are broadly grouped into qualitative and quantitative categories. Quantitative techniques are usually applied first. However, few hazards in aviation lend themselves to an analysis based only on mathematical and/or computational methods. Typically, the risk management process is supplemented through critical and logical analysis of known facts and how they may interact with each other (ICAO, 2013c; Junior et al., 2009; Vincoli, 2006). The design of a risk matrix by the flight school should consider the characteristics of the organization, including its safety culture, the specifics of its operation, and the applicable safety standards. In addition, it should define what acceptable and unacceptable risks are in order to categorize the levels of probability and severity. Many versions of risk matrices are available from the safety literature and could be used while the flight school is developing its own risk matrix (Bastos, 2005; Mendonca, 2008). After the risk assessment phase, all relevant information should be immediately promulgated within the system, and most likely will impact the safety promotion component of the SMS (see Figure 3, in the Appendix, and Figure 1). 
According to Lu and colleagues (2007), the system safety tool phase processes the information from the previous risk assessment stage, and recommends the development and implementation of safety risk controls to mitigate hazards (see Figure 2, in the Appendix). The FAA (2010) adds that system safety is a specialty within system engineering that supports the management of risks in aviation. The fault tree analysis (FTA), for example, is a system safety tool that can be used to assist in preventing accidents involving extremely complex or detailed systems, such as FAR 141 approved flight schools (see Figure 2, in the Appendix). The FTA may be used to evaluate safety risk controls necessary to result in a desired event, such as "no accident" (Vincoli, 2006). The implementation of system safety tools will allow Part 141 organizations to shift from their basic ways of addressing safety to a more detailed approach for identifying and prioritizing hazardous precedents upstream.

\section{Investigation of Safety Occurrences}

The aircraft accident investigation process must be conducted only for the purpose of prevention of future accidents. The focus of the process should be directed toward effective risk control (ICAO, 2016). According to Wells and Rodrigues (2003), the purpose of the accident investigation process is to uncover pervasive unrecognized causal factors of aircraft accidents and to recommend risk management measures. This will help prevent similar mishaps from occurring in the future. However, most safety occurrences, such as incidents caused by wildlife strikes, do not warrant investigations by either states or regulatory agencies, and perhaps even the organization. However, such incidents may reveal serious hazards and/or latent conditions that will not be disclosed unless the occurrence is adequately investigated (Cleary \& Dolbeer, 2005; Mendonca, 2008). The investigation of safety occurrences contributes to the continuous improvement of the SMS by identifying the underlying causes of the events and implementing appropriate corrective actions (FAA, 2015a; ICAO, 2013c; Lu et. al., 2007). Safety investigations can support decisions regarding the development of corrective actions and the corresponding allocation of resources. Moreover, such investigations may identify necessary improvements to the flight school SMS (ICAO, 2013c).

\section{Safety Training, Education, and Communication}

Safety promotion provides a means of encouraging a positive safety culture. Additionally, it helps personnel understand and apply the SMS principles, the safety culture concepts, and procedures and practices that create an environment conducive to the achievement of the organization's safety objectives (ICAO, 2013c; Junior et al., 2009). Safety promotion also helps the organization's professionals to understand their roles, responsibilities, and accountabilities within the SMS framework (Volkmer, 2011).
The proposed SMS framework requires that the flight school implement processes that formalize information sharing across all levels of the organization to ensure personnel are fully aware of the SMS. Those processes will also convey safety-critical information, and explain why particular safety risk controls and procedures are introduced or changed.

A flight school safety effort will not succeed solely by mandate or strict adherence to standard operating procedures (SOPs), processes, and policies (ICAO, 2013c). Rather, this is achieved through the combination of technical competence that is continually enhanced through training and education, effective communications, and information sharing. Training is the foundation of any business plan, and safety training is no exception. Excellence in activities developed by flight schools requires technical and mental skills; both are acquired and maintained through training and practice. In order for the SMS to succeed, training should be an ongoing, recurring activity, not just a onetime process (Junior et al., 2009; Mendonca, 2016). The success of the proposed SMS model depends strongly on the organization's safety culture, which in turn depends on the efficacy of the SMS training program.

\section{Performance of the Model}

The absence of accidents and incidents in an approved flight school does not necessarily indicate a safe operation (Adjekum, 2014; Adjekum et al., 2015; Cassens, 2010, 2015; Keller, 2015). In addition, the level of safety within such a dynamic type of operation is unlikely to be static. According to Junior and colleagues (2009), one essential concept addressed by SMS is continuous improvement. The elements grouped under the safety assurance pillar of the proposed SMS model provide the tools to accomplish that. In addition, this pillar aims to ensure that the processes and safety risk controls taken to enhance safety are effective (DeFusco et al., 2015; FAA, 2015b; ICAO, 2013c). As noted by Stolzer and colleagues (2010), the SA and the SRM processes in the model should be integrated for the SMS to be effective (see Figure 4, in the Appendix). Moreover, the complementary relationship between the quality assurance and safety assurance will facilitate the integration of several supporting existing processes. Such integration will serve to achieve synergies to assure that the flight school's quality, safety, and commercial objectives are met (ICAO, 2013c).

\section{Implementation of the SMS Model}

The proposed SMS model, in accordance with AC12092B, requires that the flight school develop and maintain SMS documentation that describes the certificate holder's safety policy and SMS processes and procedures (FAA, 2015b). The suggested disciplined approach to documentation and information management will provide the 
authoritative basis for the SMS, clarify the relationship of safety management to the other functions of the organization, establish the manner in which safety management activities harmonize with these other functions, and specify how the SMS activities relate to the company's safety policy. The SMS documentation will be made up of the organization's SMS manual and the specific procedures for the SMS processes. The proposed SMS model manual could be a standalone document, and if the details of the organization's SMS processes are already addressed in the existing documents, appropriate cross-referencing to such documents suffices (ICAO, 2013c). Finally, the information, records, and processes taken to fulfill the objectives of the SMS may be necessary in the event of a formal safety investigation or audit by the FAA; therefore, these data should be maintained in sufficient detail to ensure traceability of all safety-related decisions.

As an ICAO member state, the United States should, as a part of its SSP, require certain service providers under its authority to implement an SMS, or notify ICAO of any differences between their national regulations and practices and the SARPs contained in Annex 19 (ICAO, 2011; ICAO, 2013c). AC120-92B requires certificate holders operating under FAR 121 to implement and maintain an SMS by 2018. The same document could also be used by other aviation service providers interested in voluntarily developing an SMS based on the requirements in Part 5 (FAA, 2015b). It can be anticipated, considering the benefits of an SMS for aviation safety, and also to comply with Annex 19 SARPs, that the FAA will (in time) also require other service providers to implement an SMS, including FAR 141 approved flight schools.

The CFR Part 141 requirements help to ensure a high level of safety during the operations of certificated flight schools. However, several studies have identified safety issues that could contribute to aircraft accidents (Adjekum, 2014; Adjekum et al., 2015; Cassens, 2010, 2015; Keller, 2015). Recommendations by these researchers to enhance safety most likely involve at least one of the four SMS pillars. Cassens (2010) suggested that Part 141 operators should introduce processes to periodically determine the status of $\mathrm{ADM}$ instruction and whether there is a need for improvement. Those refer to the safety training and education, and the safety assurance processes of the proposed model.

Studies by Adjekum (2014) and Adjekum and colleagues (2015) addressed safety culture and SMS tenets. Both studies identified factors that could have a significant negative effect on the safety culture of pilots in collegiate aviation programs. A robust safety culture is paramount for accident prevention (Junior et al., 2009; Piers et al., 2009; Reason, 1998). The proposed SMS model, in agreement with Piers and colleagues (2009), Junior and colleagues (2009), and ICAO (2013c), will foster the development and maintenance of a healthy safety culture among Part 141 operators.
Keller's (2015) study sought to evaluate the effectiveness of two weather training protocols designed to enhance GA pilots' knowledge and abilities when encountering VMC to IMC conditions. As previously noted, such conditions have contributed to a high rate of fatal aircraft accidents. Participants of this study included Part 141 pilots. Some of them misperceived the increased risks due to degrading visibility while transitioning from VMC to IMC. Others overrelied on technology to keep them safe. Moreover, the desire to get to their final destinations played a role in the decision making processes of a few participants. Those safety hazards can increase the risk of fatal aircraft accidents. The researcher recommended enhanced safety training to mitigate such hazards. The safety training and education components of the proposed model will provide pilots the skills and knowledge to fly safely. In addition, they will enhance the safety culture of the organization.

The SMS development, implementation, and maintenance costs by Part 141 operators will depend on several factors, among them:

1. The size and complexity of the organization;

2. The existence of already mature SMS processes (e.g. safety reporting systems; ERP); and

3. The need to hire and/or provide training to SMS professionals.

However, it is estimated that the safety benefits will greatly outweigh the costs of developing and implementing an SMS. The implementation of an SMS by a Part 141 operator will help ensure that their safety efforts target the areas where safety benefits will be greatest, and therefore more effective. Additionally, it will help promote a sound safety culture within the organization. Compliance with regulations is paramount for aviation safety, but the contemporary thinking is that much more is required to prevent accidents. Organizations that simply comply with minimum standards set by regulatory agencies are not in a good position to proactively identify and mitigate safety hazards, and especially to maintain a sound safety culture (ICAO, 2013c; Mendonca, 2008). However, regulatory compliance is critical to employment orientation, initial and recurrent safety training, routine safety education, and safety-related event investigations (Lu et. al., 2007).

One benefit of an SMS, as cited by Cardoso and colleagues (2008a); the FAA (2015a); ICAO (2013b); and Ludwig and colleagues (2007) is to ensure compliance with, and wherever possible, exceed the legislative and regulatory requirements and standards (see Table 4 , in the Appendix). Therefore, the proposed model will help the approved flight school to comply with national regulations and international standards.

\section{Conclusions}

International aviation organizations, safety specialists, and regulatory authorities have established that SMS 
represents the future of the management of safety for the aviation industry (Volkmer, 2011; Walala, 2015). SMS concepts have been applied in many countries and are gaining acceptance in the US as a standard. In order to comply with ICAO SARPs, the US should, as part of their SSP, require that FAR 141 approved flight schools, among other service providers, develop and implement an SMS. The SMS should, at a minimum, identify and mitigate safety hazards; ensure that safety risk controls necessary to maintain an acceptable level of safety are implemented; and make continuous improvement to the overall level of safety (ICAO, 2013b; ICAO, 2013c). The ICAO Global Aviation Safety Plan establishes the global aviation safety objectives, including the specific priorities and milestones to be addressed by ICAO member states (ICAO, 2013a). The United States should have a fully implemented and mature SSP by 2022. Therefore, Part 141 operators (ICAO, 2013c) will most likely be required to have an SMS by the same date. As previously mentioned, the SSP provisions in ICAO Annex 19 require the implementation of SMS by some aviation organizations under the responsibility of each ICAO member state. Even though there is a significant body of literature and regulations addressing the concepts of SMS, none really provides a model that could be used to manage safety risks in approved flight schools. There are at least four major reasons why the implementation of the proposed model by approved flight schools goes beyond regulatory compliance. To begin with, safety is an intrinsic component of the aviation system. This scheme becomes of key importance if one considers that international air traffic has doubled in size every 15 years since 1977, and that between 2013 and 2030 it is expected to double again (ICAO, 2014). The 3.5 billion airline passengers carried in 2015 are expected to triple by 2040 (ICAO, 2015). In addition, the number of aircraft movements is expected to rise to almost 95 million in 2040. According to the FAA (2014), the number of passengers carried annually by U.S. FAR 121 carriers is slated to grow 2.2 percent per year until 2034, and the U.S. aviation system capacity is projected to increase an average of 2.7 percent per year during the same period. This projected growth in both the international and U.S. aviation systems will certainly increase the amount of flight training performed by approved flight schools. Secondly, SMS is also very attractive because of its resulting economic advantages in preventing mishaps. For example, a research study developed by Landry and Ingolia (2011) showed that ground accidents are extremely costly to the aviation industry. Furthermore, such accidents are estimated to account for an astonishing $\$ 10$ billion a year, with only a fraction of those costs covered by insurance. Another study conducted by the Flight Safety Foundation (2007) puts a cost of \$1 billion per year due to this type of occurrence with corporate aircraft operators worldwide. The implementation of an effective SMS by airport operators in South America led to a $21 \%$ reduction in this type of occurrence in eight months (Cardoso et al., 2008a). The third reason is that this model may be an excellent tool to develop and maintain a robust safety culture that raises safety awareness, and results in a reduction of accidents, injuries, and related costs (Stolzer et al., 2010). Fourth, the proposed model combines the ICAO and FAA requirements, and considers existing safety programs and processes that may be integrated into the flight school SMS. That will assure compliance with national and international standards while facilitating the development and implementation of an SMS by approved flight schools.

Finally, from a purely business point of view, there is no reason to wait to improve efficiency and effectiveness, and to reduce safety risks. Implementing the proposed SMS model has a cost, but it is infinitely smaller than the costs associated with aircraft accidents and incidents. Improving the efficiency and effectiveness of the organization will lead to increased profits by approved flight schools. Further benefits will include the potential for reduced insurance costs; research opportunities for faculty and students; opportunities for faculty, staff, and students to gain SMS experience; and an enhanced recruiting tool for parents and prospective students. Most importantly, as previously noted, is the potential for SMS to enhance aviation safety.

\section{References}

Adjekum, D. K. (2014). Safety culture perceptions in a collegiate aviation program: A systematic assessment. Journal of Aviation Technology and Engineering, 3(2), 44-56.

Adjekum, D. K., Keller, J., Walala, M., Young John, P., Christensen, C., DeMik, R. J., \& Northam, G. J. (2015). Cross-sectional assessment of safety culture perceptions and safety behavior in collegiate aviation programs in the United States. International Journal of Aviation, Aeronautics, and Aerospace, 2(4), 1-34. https://doi.org/10.15394/ijaaa. 2015.1074

Air Safety Institute. (2016). Accident analysis: Accident database. Retrieved from https://www.aopa.org/asf/ntsb/search_ntsb.cfm

Antonsen, S. (2009). Safety culture assessment: A mission impossible? Journal of Contingencies and Crisis Management, 17(4), 242-254.

Bastos, L. C. M. (2005). Risk management model for on-demand Part 135 (air taxi) operators (Unpublished master's thesis). University of Central Missouri, Warrensburg, MO.

Berg, B. L. (2001). Qualitative research methods for the social sciences (4th Ed.). Needham Heights, MA: Allyn \& Bacon.

Cardoso, S. H., Maurino, D., \& Fernandez, J. (2008a, May). Lessons learnt from airport SMS implementation in South America. Presented at the $10^{\text {th }}$ International Conference on Applications of Advanced Technologies in Transportation (AATT), Athens, Greece.

Cardoso, S. H., Maurino, D., \& Fernandez, J. (2008b, January). Methodology to Estimate Individual and Overall Performance Indicators for Airport Safety Management Systems (SMS). Paper presented at the 87th Transportation Research Board Annual Meeting, Washington, DC.

Cassens, R. E. (2010). Elements related to teaching pilots aeronautical decision making. (Unpublished master's thesis). Purdue University, West Lafayette, IN.

Cassens, R. E. (2015). The effectiveness of behavior-based safety in the flight training environment (Unpublished doctoral dissertation). Purdue University, West Lafayette, IN. 
Chen, C. F., \& Chen, S. C. (2014). Measuring the effects of safety management system practices, morality leadership and self-efficacy on pilots' safety behaviors: Safety motivation as a mediator. Journal of Safety Science, 62, 376-385. https://doi.org/10.1016/j.ssci.2013.09.013

Choudhry, R. M., Fang, D., \& Mohamed, S. (2007). The nature of safety culture: A survey of the state-of-the-art. Journal of Safety Science, 45, 993-1012. https://doi.org/10.1016/j.ssci.2006.09.003

Cleary, E. C., \& Dolbeer, R. A. (2005). Wildlife hazard management at airports: A manual for airport personnel. Retrieved from http://about/ airports/airport_safety/wildlife/resources/media/2005_faa_manual_ complete.pdf

Cooper, M. D. (2000). Towards a model of safety culture. Safety Science, $36(2), 111-136$.

Decrop, A. (1999). Triangulation in qualitative tourism research. Tourism Management, 20(1), 157-161.

DeFusco, R. P., Junior, E. T. U., Cooley, T. R., \& Landry, J. M. (2015). Applying an SMS approach to wildlife hazard management (ACRP Report No. 145). Retrieved from the Transportation Research Board on the National Academies website: http://onlinepubs.trb.org/onlinepubs/ acrp/acrp_rpt_145.pdf

Department of Transportation (DOT). (2015). Safety management systems for domestic, flag, and supplemental operations certificate holders. Retrieved from https://www.gpo.gov/fdsys/pkg/FR-2015-01-08/pdf/ 2015-00143.pdf

Electronic Code of Federal Regulations, Title 14, Chapter I, Subchapter H, Part 141. (2015). Available online at http://www.ecfr.gov/cgi-bin/textidx?tpl=/ecfrbrowse/Title14/14cfr141_main_02.tpl

Federal Aviation Administration (FAA). (1991). Aeronautical decision making (Advisory Circular 60-22B). Retrieved from http://about/ documentLibrary/media/ Advisory_Circular/AC_60-22.pdf

Federal Aviation Administration (FAA). (2009). Risk management handbook (FAA-H-8083-2). Retrieved from https://about/regu lations_policies/handbooks_manuals/aviation/media/FAA-H8083-2.pdf

Federal Aviation Administration (FAA). (2010). System safety handbook. Retrieved from http://about/regulations_policies/handbooks_manuals/ aviation/risk_management/ss_handbook/

Federal Aviation Administration (FAA). (2014). FAA aerospace forecast: Fiscal years 2014-2034. Retrieved from https://about/data_research/ aviation/aerospace_forecasts/media/2014_FAA_Aerospace_Forecast. pdf

Federal Aviation Administration (FAA). (2015a). Aviation emissions, impact \& mitigation: A primer. Retrieved from http://about/ regulations_policies/policy_guidance/envir_policy/media/primer_ jan2015.pdf

Federal Aviation Administration (FAA). (2015b). Safety management systems for aviation service providers (Advisory Circular 120-92B). Retrieved from http://www.faa.gov/regulations_policies/advisory_ circulars/index.cfm/go/document.information/documentID/1026670

Federal Aviation Administration (FAA). (2015c). Safety management system: Voluntary implementation of SMS for Non-Part 121 operators, $M R O s$, and training organizations. Retrieved from http://about/ initiatives/sms/specifics_by_aviation_industry_type/air_operators/

Federal Aviation Administration (FAA). (2016). Pilot's handbook of aeronautical knowledge. Retrieved from https://about/regulations_ policies/handbooks_manuals/aviation/phak/

Flight Safety Foundation. (2007, May). Defusing the ramp. AeroSafetyWorld, 2(5). Retrieved April 15, 2016, from http://flightsafety.org/asw/ may07/asw_may07_p20-24.pdf

Foxx, A. (2015, February). Safety News: SMS by 2018. AeroSafetyWorld, 10(1). Retrieved from http://flightsafety.org/aerosafety-world-february2015

Freiwald, D., Anderson, C. L., \& Baker, E. (2013). Assessing safety culture within a flight training organization. Journal of Aviation/Aerospace Education and Research, 22(2), 41-57.
Galotti, V., Rao A., \& Maurino, D. (2006). ICAO initiative promotes global approach to SMS implementation. ICAO Journal, 61(6), 6-8. Retrieved from http://www.icao.int/publications/journalsreports/2006/ 6106_en.pdf

Gnehm, E. (2013). Annex 19: A key amendment to the convention. ICAO Journal, 68(05), 60-63. Retrieved from http://www.icao.int/publica tions/journalsreports/2013/6805_en.pdf

Graham, N. (2015). High-level safety event takes urgent action while respecting strategic goals. ICAO Journal, 70(1), 6-8. Retrieved from http://www.icao.int/publications/journalsreports/2015/7001_en.pdf

International Civil Aviation Organization (ICAO). (2005). ICAO accident prevention programme (2nd ed.). Montreal, Canada: Author.

International Civil Aviation Organization (ICAO). (2011). Annex 1 to the Convention on International Civil Aviation, Personnel Licensing (11th ed.). Montreal, Canada: Author.

International Civil Aviation Organization (ICAO). (2012). Safety management implementation: Preliminary review of proposed new Annex on safety management responsibilities and processes (AN-WP/8633). Montreal, Canada: Author.

International Civil Aviation Organization (ICAO). (2013a). Global aviation safety plan 2014-2016. Montreal, Canada: Author.

International Civil Aviation Organization (ICAO). (2013b). ICAO safety management manual (3rd ed.). Montreal, Canada: Author.

International Civil Aviation Organization (ICAO). (2013c). Annex 19 to the Convention on International Civil Aviation, Safety Management (1st ed.). Montreal, Canada: Author.

International Civil Aviation Organization (ICAO). (2014). Annual report of the ICAO Council-2014: The world of air transport in 2014. Retrieved from http://www.icao.int/annual-report-2014/Pages/theworld-of-air-transport-in-2014.aspx

International Civil Aviation Organization (ICAO). (2015). Annual report of the ICAO Council-2015: The world of air transport in 2015. Retrieved from http://www.icao.int/annual-report-2015/Pages/theworld-of-air-transport-in-2015.aspx

International Civil Aviation Organization (ICAO). (2016). Annex 13 to the Convention on International Civil Aviation, Aircraft Accident and Incident Investigation (11th ed.). Montreal, Canada: Author.

Johnson, M., \& Gonzalez, A. (2013). Estimating cost saving for aviation fuel and $\mathrm{CO} 2$ emission reduction strategies. Collegiate Aviation Review, 31(2), 79-102

Junior, M. A., Shirazi, H., Cardoso, S., Brown, J., Speir, R., Seleznev, O., ... McCall, E. (2009). Safety management systems for airports (ACRP Report No. 01, volume 2). Retrieved from the Transportation Research Board on the National Academies website: http://www.trb. org/main/blurbs/162491.aspx

Keller, J. (2015). Unexpected transition from VFR to IMC: An examination of training protocols to mitigate pilot gaps in knowledge and performance (Unpublished doctoral dissertation). Purdue University, West Lafayette, IN.

Landry, J., \& Ingolia, S. (2011). Ramp safety practices: A synthesis of airport practice (ACRP Synthesis No. 29). Retrieved from the Transportation Research Board on the National Academies website: http://www.trb.org/main/blurbs/166314.aspx

Leedy, P. D., \& Ormrod, J. L. (2005). Practical research: Planning and design. Upper Saddle River, NJ: Pearson Education.

Liou, J. J. H., Yen, L., \& Tzeng, G. H. (2008). Building an effective safety management system for airlines. Journal of Air Transport Management, 14, 20-26. https://doi.org/10.1016/j. ssci.2013.09.013

Lu, C-t., Bos, P., \& Caldwell, W. (2007). System safety application: Constructing a comprehensive aviation system safety management model (ASSMM). International Journal of Applied Aviation Studies, 7(1), 28-45.

Lu, C-t., Wetmore, M., \& Przetak, R. (2006). Another approach to enhance airline safety: Using management safety tools. Journal of Air Transportation, 11(2), 113-139. 
Ludwig, D. A., Andrews, C. R., Veen, N. R. J., \& Laqui, C. (2007). Safety management systems for airports (ACRP Report No. 01, volume 1). Retrieved from the Transportation Research Board on the National Academies website: http://www.trb.org/Main/Blurbs/159030.aspx

Lupoli, L. C. (2006). Discovering the Brazilian Air Force Squadron Commander's perceptions regarding organizational accidents (Unpublished master's thesis). University of Central Missouri, Warrensburg, MO.

Manuele, F. A. (2003). On the practice of safety (3rd Ed.). New York: International Thomson Publishing Company.

Maurino, D. E., Reason, J., Johnston, N., \& Lee, R. B. (1995). Beyond aviation human factors. Aldershot, UK: Ashgate.

Mendonca, F. A. C. (2008). SMS for bird hazard: Assessing airlines pilots' perceptions (Unpublished master's thesis). University of Central Missouri, Warrensburg, MO.

Mendonca, F. A. C. (2016). Exploiting science: Enhancing pilots' safety training to reduce the risk of bird strikes. Paper presented at the 2016 Bird Strike Committee USA Meeting, Chicago, IL. Presentation retrieved from http://www.aaae.org/aaae/AAAEDocs/Meetings/2016/08/ 160807/Pres/26_Mendonca.pdf

Patton, M. Q. (2015). Qualitative research \& evaluation methods. London: SAGE.

Piers, M., Montijn, C., \& Balk, A. (2009). Safety culture framework for the ECAST SMS-WG. Report of the ECAST safety management system and safety culture working group (SMS-WG). Retrieved from http://www. atcvantage.com/docs/culture_NLR_SafetyCultureFramework_WP1ECASTSMSWG-1.pdf

Reason, J. (1997). Managing the risks of organizational accidents. Aldershot, UK: Ashgate.
Reason, J. (1998). Achieving a safe culture: Theory and practice. Journal of Work and Stress, 12(3), 293-306. https://doi.org/10.1080/0267837 9808256868

Stolzer, A. J., Halford, C. D., \& Goglia, J. J. (2010). Safety management systems in aviation. Aldershot, UK: Ashgate.

Vincoli, J. W. (2006). Basic guide to system safety (2nd Ed.). Hoboken, NJ: John Wiley \& Sons.

Volkmer, F. L. (2011). Revising the hazard report program with safety management system perspective: Assessing Brazilian Air Force safety specialists' perceptions (Unpublished master's thesis). University of Central Missouri, Warrensburg, MO.

Walala, M. S. (2016). A cross-sectional and mixed-method assessment of safety culture and safety climate at a regional airline (Unpublished doctoral dissertation). Purdue University, West Lafayette, IN.

Wells, A. T., \& Rodrigues, C. C. (2003). Commercial aviation safety. New York: McGraw-Hill.

Wells, A. T., \& Wensveen, J. G. (2004). Air transportation: A management perspective. Belmont, CA: Thomson Learning.

Wiegmann, D. A., Thaden, T. L. V., \& Gibbons, M. A. (2007). A review of safety culture theory and its potential application to traffic safety. Retrieved from the Transportation Research Board on the National Academies website: http://trid.trb.org/view.aspx?id=809716

Wood, R. H. (2003). Aviation safety programs: A management handbook. Englewood, CO: Jeppesen Sanderson.

Wood, R. H., \& Swegininis. (2006). Aircraft accident investigation. Casper, WY: Endeavor Books.

Yin, R. K. (5th Ed). (2014). Case study research: Design and methods. Beverly Hills, CA: Sage.

\section{Appendix}

Table 1

Characteristics of different safety cultures.

\begin{tabular}{lccc}
\hline \multicolumn{1}{c}{$\boldsymbol{I}$} & POfety Culture Characteristics $\rightarrow$ & BUREAUCRATIC & HEALTHY \\
\hline Hazard information is & Suppressed & Ignored & Actively sought \\
Safety messages are & Discouraged or punished & Tolerated & Trained and encouraged \\
Responsibility for safety is & Avoided & Cover-ups & Rewarded \\
Failures lead to & Crushed & Considered as new problems & Inquiries and systemic reform \\
New ideas are & Really welcomed \\
\hline
\end{tabular}

Note. This table was adapted from the "ICAO Accident Prevention Programme," by ICAO, 2005, Montreal, Canada: Author. 


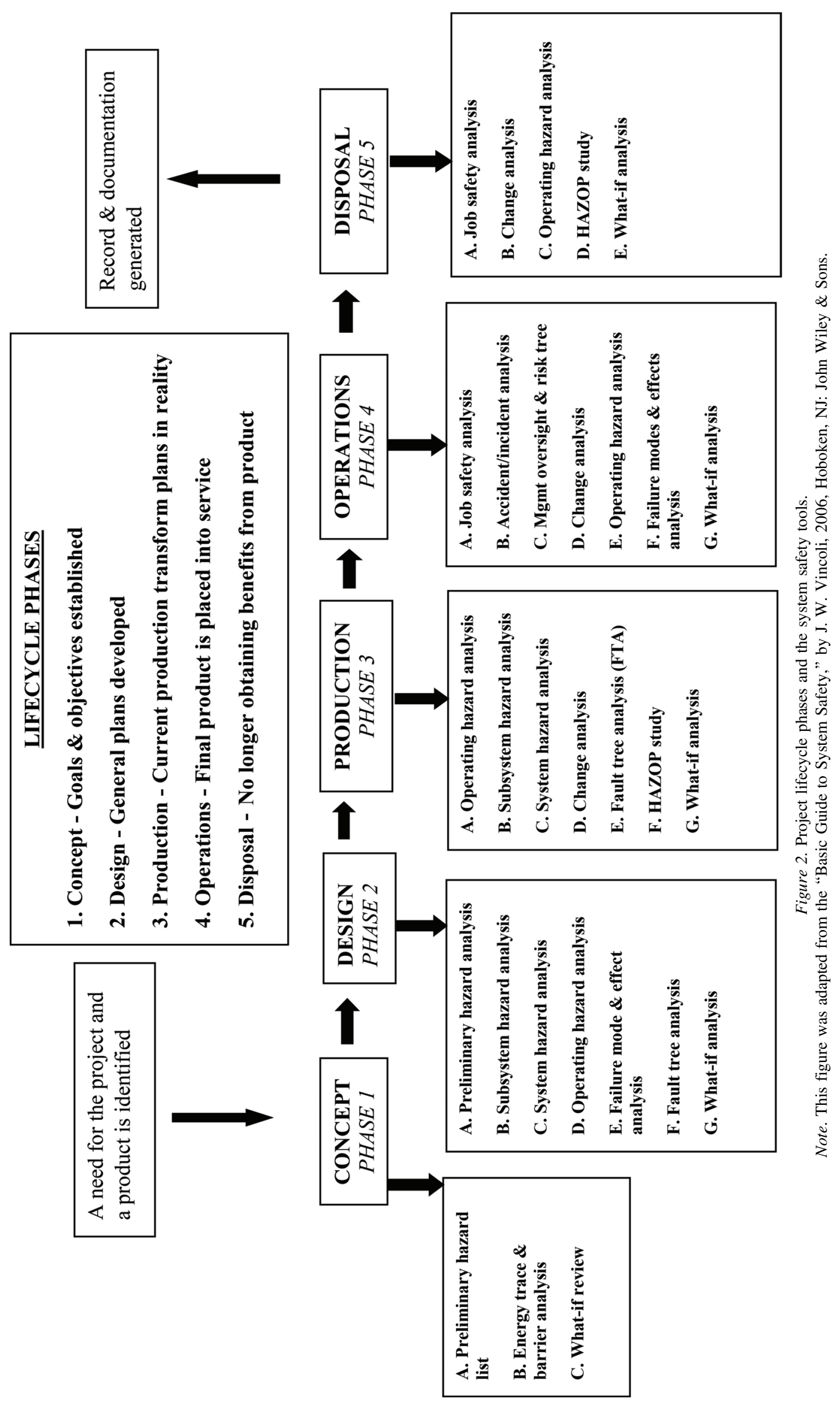


Table 2

Components and elements of an SMS.

\begin{tabular}{ll}
\hline COMPONENTS & ELEMENTS \\
\hline Safety policy and objectives & $\begin{array}{l}\text { Management commitment and responsibility } \\
\text { Safety accountabilities } \\
\text { Appointment of key safety personnel }\end{array}$ \\
& $\begin{array}{l}\text { Coordination of emergency response planning } \\
\text { SMS documentation }\end{array}$ \\
Hafety risk management & $\begin{array}{l}\text { Hazard identification } \\
\text { Assessment and mitigation }\end{array}$ \\
Safety assurance & Safety performance monitoring and measurement \\
& The management of change \\
Continuous improvement of the SMS & Training and education \\
& Safety communication
\end{tabular}

Note 1. This table specifies the framework for the implementation and maintenance of an SMS. The framework comprises four components and twelve elements as the minimum requirements for SMS implementation.

Note 2. This table was adapted from the "ICAO Annex 19," by ICAO, 2013c, Montreal, Canada: Author.

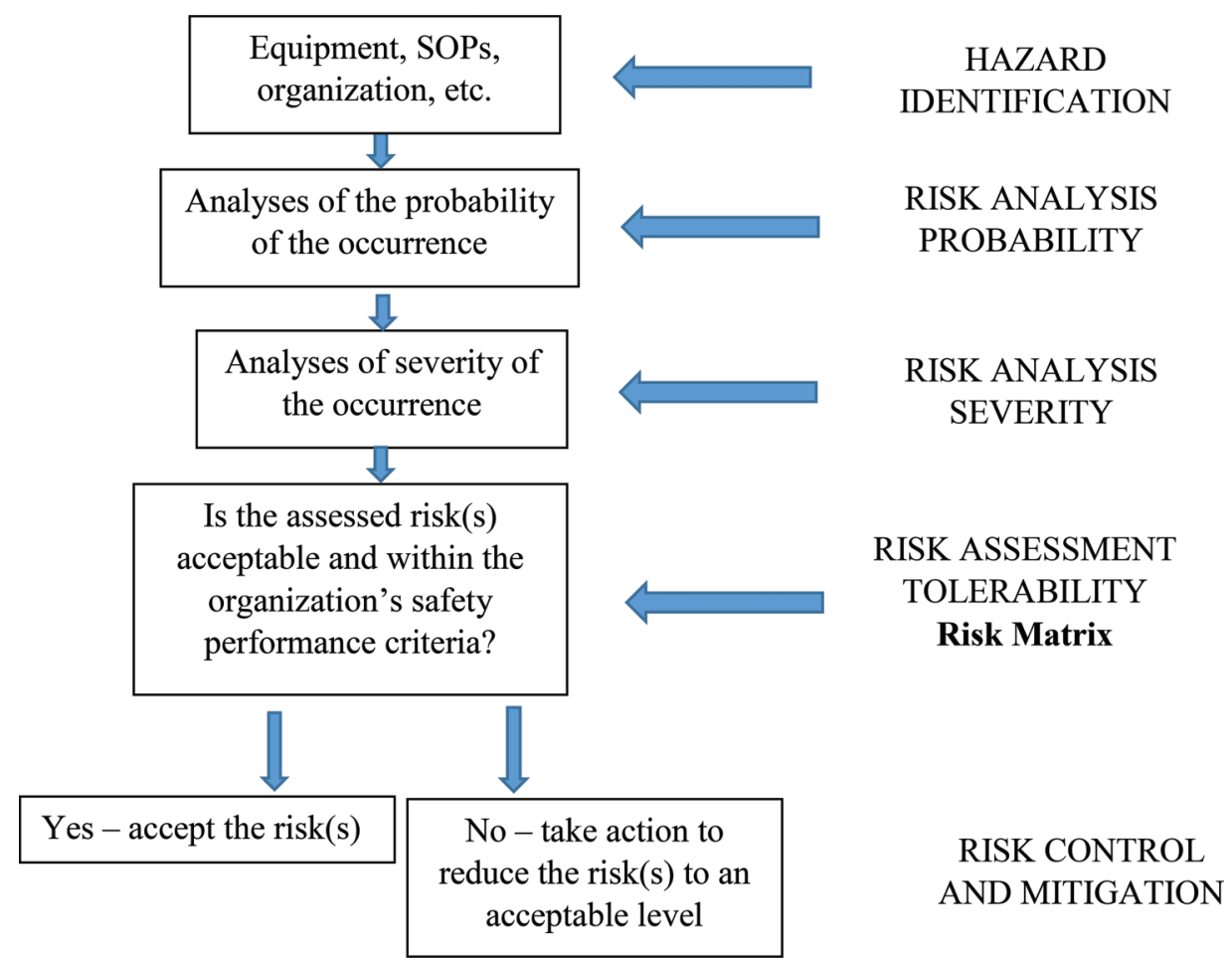

Figure 3. The safety risk management process.

Note. This process was adapted from the "ICAO Safety Management Manual," by ICAO, 2013b, Montreal, Canada: Author. 
Table 3

Existing processes and programs that could be integrated to the SMS in order to satisfy the FAA SMS requirements.

\begin{tabular}{|c|c|c|}
\hline PROGRAM & OBJECTIVE & SMS INTEGRATION \\
\hline $\begin{array}{l}\text { Aviation Safety Action Program } \\
(\text { ASAP) })^{\mathrm{a}}\end{array}$ & $\begin{array}{l}\text { ASAP is designed to encourage voluntary } \\
\text { reporting of safety issues and events that come to the } \\
\text { attention of participating certificate holders' personnel }\end{array}$ & $\begin{array}{l}\text { Partially satisfies the requirement for a confidential } \\
\text { reporting system }\end{array}$ \\
\hline $\begin{array}{l}\text { Aviation Safety Reporting } \\
\text { System (ASRS) }\end{array}$ & $\begin{array}{l}\text { Allows aviation professionals to report to the National } \\
\text { Aeronautics and Space Administration (NASA) } \\
\text { actual or potential discrepancies and deficiencies } \\
\text { involving the safety of aviation operations in the } \\
\text { interest of improving aviation safety }\end{array}$ & $\begin{array}{l}\text { Trend and global systemic information may be } \\
\text { appropriate for safety assurance (SA) }\end{array}$ \\
\hline $\begin{array}{l}\text { Voluntary Disclosure Reporting } \\
\text { Program (VDRP) }\end{array}$ & $\begin{array}{l}\text { Provides incentives for a certificate holder to } \\
\text { voluntarily identify, report, and correct } \\
\text { instances of regulatory noncompliance }\end{array}$ & $\begin{array}{l}\text { Data gathered during an investigation, subsequent } \\
\text { development, and implementation of a fix could } \\
\text { be integrated into the data analysis, assessment, } \\
\text { and validation processes of an approved flight } \\
\text { school's SMS SA }\end{array}$ \\
\hline Emergency response plan $(\mathrm{ERP})^{\mathrm{b}}$ & $\begin{array}{l}\text { Provides for the orderly and efficient transition } \\
\text { from normal to emergency operations and the } \\
\text { return to normal operations }\end{array}$ & $\begin{array}{l}\text { It may satisfy the safety policy ERP component of } \\
\text { an SMS }\end{array}$ \\
\hline Quality management systems (QMS) ${ }^{\mathrm{b}}$ & $\begin{array}{l}\text { Provides consistency in the delivery of products and } \\
\text { services to meet performance standards as well as } \\
\text { customer expectations }\end{array}$ & $\begin{array}{l}\text { SMS and QMS utilize similar risk management and } \\
\text { assurance processes (can be integrated in both } \\
\text { processes) }\end{array}$ \\
\hline PART 141 requirements ${ }^{c}$ & $\begin{array}{l}\text { Prescribes the requisites for issuing pilot school } \\
\text { certificates, provisional pilot school certificates, } \\
\text { and associated ratings, and the general operating } \\
\text { rules applicable to a holder of a certificate or rating } \\
\text { issued under this part }\end{array}$ & $\begin{array}{l}\text { Many requirements could be used to satisfy the } \\
\text { AC120-92B (e.g., Part 141 Subpart A § } 141.21 \\
\text { and Subpart F, and AC120-92B § 5.23) }\end{array}$ \\
\hline
\end{tabular}

Note. ${ }^{\mathrm{a}}$ (FAA, 2015b), ${ }^{\mathrm{b}}$ (ICAO, 2013c), ${ }^{\mathrm{c}}$ (Electronic Code of Federal Regulations, Title 14, Chapter I, Subchapter H, Part 141, 2015)

Table 4

Benefits of SMS implementation.

ICAO FAA $\quad$ FAdwig et al.

Provides for the investigation of accidents. Yet, it will lower the consequence of events

Eliminates potentially conflicting responsibilities and relationships

Reduces organizational risks and increases profitability

Promotes the integration of the different organizations' management systems

Ensures compliance with and, wherever possible, exceeds legislative and regulatory requirements and standards

Introduces supplementary performance-based elements for more effective control of safety risks

Encourages and facilitates the implementation of a positive safety culture

Establishes and implements processes and procedures that facilitate effective communication and down the organization and among peers throughout all levels of the organization

Ensures safety is a primary responsibility of all managers

Ensures that personnel understand that safety is an essential part of their job performance
Reduces the direct and indirect costs of mishaps

Promotes the active involvement of the operational leaders

Identifies risks in operations and reduces them to an acceptable level

Ensures that safety information undergirds the decision making process by all levels of management

Assists service providers in meeting regulatory requirements

Reduces insurance and liability costs

Promotes the development, implementation, and, maintenance of a healthy safety culture

Maintains open lines of communication up
Improves employee morale and productivity

Establishes a marketable safety record

Ensures logical prioritization of safety needs

Assures compliance with legal responsibilities for safety

Provides more efficient maintenance scheduling and resource utilization

Spreads responsibility for safe operations throughout all levels and segments of the organization

Promotes the continuous improvement of operational processes

Avoids incident investigation costs and operational disruptions

Note 1. This table was adapted from the following: "ICAO Annex 19," by ICAO, 2013a, Montreal, Canada: Author; "AC-120-92B," by the FAA, 2015a; and from the "Safety Management Systems for Airports," by Ludwig et al., 2007, Transportation Research Board.

Note 2. Cardoso and colleagues (2008a) also suggest that an SMS can reduce the costs of aircraft accidents and incidents and related disruptions; improve employee morale and productivity; improve the logical prioritization of safety needs; provide more efficient maintenance scheduling and resource utilization; and promote the continuous improvement of operational processes. 


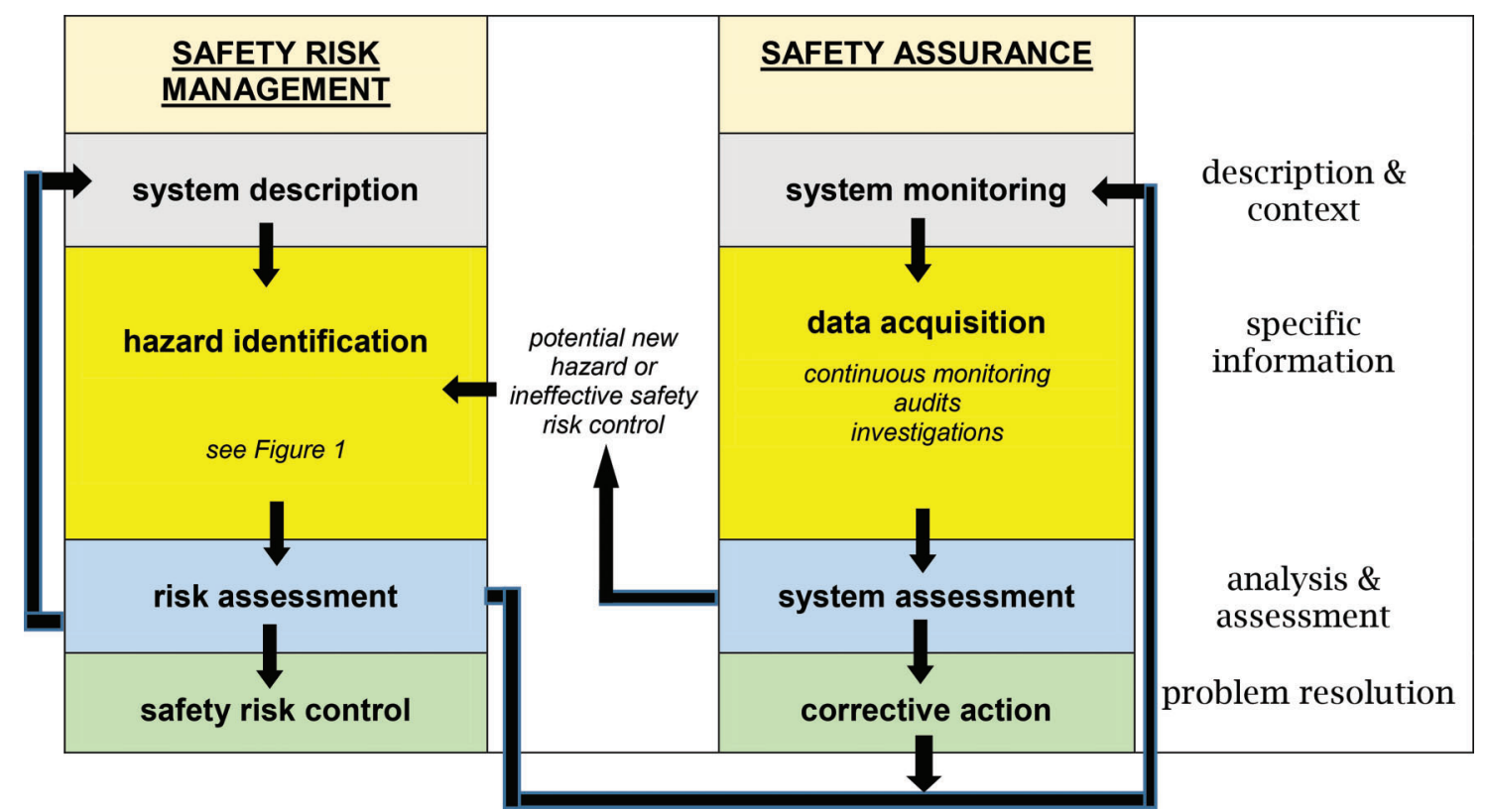

Figure 4. Integration of safety risk management and safety assurance.

Note 1. The SRM process provides for the identification of safety hazards and assessment of risk. Safety risk controls capable of bringing the risk to an acceptable level are developed by using system safety tools, and then they are employed operationally. The safety assurance function takes over at this point to ensure that the safety risk controls are being practiced and will continue to achieve their intended objectives. If this is not the case, the safety assurance process needs to determine if the shortfall is because the controls are not being used as intended (e.g., required training not accomplished, lack of or poor procedures, inadequate tools or equipment provided), or if, even though the system is being used as intended, it is not producing the expected results. In the former case, action should be taken to correct the problem, corrective action(s). In the latter case, the system design should be reconsidered using the path back to the SRM process (FAA, 2015b).

Note 2. This system also provides for assessment of the need for new controls because of changes in the operational environment.

Note 3. This Figure was adapted from the "Safety Management Systems in Aviation," by A. J. Stolzer, C. D. Halford, and J. J. Goglia, 2010, Aldershot, UK: Ashgate; and from AC120-92B, by the FAA, 2015b.

Flavio A. C. Mendonca is currently a PhD candidate at Purdue University in West Lafayette, IN. He holds an Airline Transport Pilot certificate with over 30 years of experience as a Brazilian Air Force pilot, and an MS degree in aviation safety from the University of Central Missouri. He is a master aircraft accident investigator and has been the investigator-incharge in several major accidents, including mishaps involving Part 121 operators. He participated in the International Civil Aviation Organization (ICAO) Safety Management Panel as a Brazilian representative providing expertise related to aviation safety during the development of the first edition of Annex 19, Safety Management. His primary research areas of interest include aviation safety, wildlife hazard to aviation, safety management systems, human factors, and aviation security.

Thomas Q. Carney is a professor of aviation and transportation technology at Purdue University in West Lafayette, IN. He holds an Airline Transport Pilot certificate with more than 48 years of experience as a pilot, and $\mathrm{MS}$ and $\mathrm{PhD}$ degrees in atmospheric science. His primary research areas of interest include aviation meteorology, synoptic-scale dynamics and energetics, the use of aircraft for airborne research applications, and pilots' use of weather technology in the cockpit. 